\title{
MODOS DE APLICAÇÃO AO SOLO, DE MATERIAIS CORRETIVOS DA ACIDEZ ( $\left.{ }^{1}\right)$
}

Hermano Gargantini, engenheiro-agrônomo, Seção de Fertilidade do Solo, A. Gentil Gomes, cngcnheiro-agrônomo $\left({ }^{2}\right)$ e H. Garcia Blanco, engenheiro-agrônomo $\left({ }^{3}\right)$, Seção de Fertilidade do Solo, Instituto Agronômico

\section{RESUMO}

Com a finalidade de estudar os efeitos do modo de aplicação de calcário ao solo, para correção da acidez, foi instalado o experimento relatado neste trabalho.

$O$ ensaio foi conduzido durante cêrca de dois anos $\mathrm{cm}$ solo da série Pinda, na Estação Experimental do Departamento da Produção Animal, município de Pindamonhangaba. O calcário foi aplicado antes da aradura, antes da primeira gradagem, antes da segunda gradagem ou parceladamente, metade antes da aradura e metade antes da segunda gradagem.

Em todos os tratamentos o corretivo mostrou efcito altamente significativo na redução da acidez do solo. Nos primeiros meses, houve diferenças sensíveis cutre os tratamentos. A aplicação parcelada apresentou reação mais rápida, diferenciando-se já no primeiro mês. No terceiro mês, observou-se igualdade de respostas entre os tratamentos que receberam calcário antes da aradura e parceladamente. Estes se mostraram superiores aos tratamentos que receberam calcário antes da primeira ou da segunda gradagem, que se comportaram igualmente. Entre o sétimo e o nono mês após a ap̣licação, todos os tratamentos se igualaram.

\section{1 - INTRODLÇÃO}

A aplicação de materiais corretivos ao solo, com o objetivo de corrigir a acidez excessiva e nociva ao bom desenvolvimento e produção das culturas, ou mesmo para propiciar às plantas os elementos nutritivos cálcio e magnésio, tem sido um assunto muito estudado em todo o mundo. A literatura existente sôbre os efeitos da calagem no solo e na planta, tamanho das partículas, competição de materiais corretivos e outros aspectos dessa prática agrícola, é bastante grande. No

(1) Recebido para pưblicação em 5 de agôsto de $r 965$.

(2) Jesignado pelo Instituto Agronomico, para colaborar nos projetos agronômicos dos Servicos do Vale do Paraíba, do Depártamento de Aguas e Energia Elétrica. Instituto.

(a) Atualmente pertence ao quadro de técnicos da Seção de Climatologia Agrícola, dêste 
entanto, sôbre o método de aplicação dos materiais corretivos, para melhor produzirem seus efeitos, a literatura é bastante limitada.

Millar e Turk (5), discorrendo sôbre a forma de aplicação de calcário, dizem que o fator importante ć a obtenção de uma uniforme distribuição e perfeita mistura do corretivo com o solo. Mostram que o movimento do calcário, horizontalmente, é mínimo. Sòmente o movimento vertical é apreciável. Mesmo assim, êsse movimento não é suficiente para boa distribuição do material; daí a necessidade do intimo contato das partículas de solo com o corretivo. Não esclarecem, porém, como fazer a distribuição e a mistura com o solo.

Worthen e Aldrich (7) apresentam o resultado de três formas de aplicação. Na primeira, o calcário é aplicado uniformemente sôbre o terreno, após o que se procedem às araduras e gradagens para duas culturas sucessivas. Obtém-se, no terceiro plantio, uma boa mistura da camada arável do solo com o material corretivo. No segundo processo, faz-se a aplicação antes da aradura e gradagem do terreno. O material aplicado localiza-se em faixas mais concentradas sôbre os montículos de terra formados pela aradura. Não há, assim, perfeita mistura do solo com o calcário. Finalmente, o terceiro processo corresponde à aplicação do calcário sôbre o terreno já arado. Procedendo-se. a seguir, à gradagem, obtém-se uma mistura do solo com o calcário, na camada superficial de 5,0 a $7,5 \mathrm{~cm}$ de profundidade.

Buckman e Brady (1) dizem que uma ação rápida da calagem se faz sentir quando o material corretivo é aplicado após o terreno ter sido arado. A gradagem, necessária ao preparo do terreno para o plantio, propicia boa mistura do solo com o corretivo. Dizem, ainda, que muitas vêzes é mais conveniente aplicar o calcário, procedendo-se. a seguir. à aradura do terreno.

Mikkelson, Freitas e McClung (4) afirmam que a aplicação de calcário em duas vèzes, metade antes da aradura e metarle antes da gratdagem, apresentou melhores resultados do que quando integralmente incorporado ao solo, na gradagem. (O algodão, no primeiro caso, produziu $80 \%$ mais que no segundo.

Malavolta (3) diz ser necessário aplicar o calcário a lanço por tôda a superfície do terreno, após o que deve ser gradado por duas vêzes, para perfeita incorporação do corretivo ao solo e melhor efeito do material. 
Longenecker e Merkle (2), em experimentos conduzidos em vasos, mostram que a difusão do calcário no solo é extremamente lenta, seja horizontal ou verticalmente. Os ensaios, bastante interessantes, permitiram concluir que os efeitos dos corretivos, no solo, intensificam-se quando há perfeita mistura e intimo contato entre os dois materiais.

Com o objetivo de contribuir para o conhecimento do melhor modo de aplicação de calcário ao solo, para redução de sua acidez, é que foi conduzido o presente experimento.

\section{2 - MATERIAIS E MÉTODOS}

O ensaio relatado no presente trabalho foi conduzido na Estação Experimental do Departamento da Produção Animal ( ${ }^{4}$ ), município de Pindamonhangaba. O solo escolhido foi classificado e mapeado por Verdade e outros (6) como série Pinda.

O delineamento experimental utilizado, de blocos ao acaso, constou de cinco tratamentos, sem repetições:

1. Sem calcário (testemunha)

2. Calcário antes da aradura

3. Calcário antes da primeira gradagem

4. Calcário antes da segunda gradagem

5. Calcário, meía dose antes da aradura e meia dose antes da segunda gradagem.

Procurou-se, com êsses tratamentos, estudar formas práticas de aplicação e sua influência na correção da acidez, através de determinações dos valores de $\mathrm{pH}$ do solo.

O tratamento 1, testemunha, recebeu tôdas as práticas que os demais, com exceção do calcário. No tratamento 2, espalhou-se uniformemente a quantidade total de calcário pela superfície do terreno, após o que se procedeu à aradura, seguida de duas gradagens. Nos tratamentos 3 e 4 , a quantidade total de calcário foi distribuída também uniformemente pela superfície do terreno, após a aradura, no primeiro, e após a gradagem, no segundo. Finalmente, no tratamento 5, distribuiu-se a metade da dose sôbre o solo, procederam-se à aradura e gradagem,

(1) Os autores agradecem a colaboraçāo do Dr. Raul Nélson Guaragna, Diretor da Estação Experimental, cujo auxílio tornou possível a realizaçăo dếste trabalho. 
após o que, aplicou-se a outra metade do corretivo, seguindo-se nova gradagem. Com estas operações, procurou-se promover uma perfeita mistura do corretivo com o solo.

Cada parcela do ensaio mediu $20 \times 30 \mathrm{~m}$, o que permitiu trato mecânico. O material utilizado foi um calcário dolomítico, procedente de jazida existente em Taubaté. Baseado nos valores de $\mathrm{pH}$ e $\mathrm{H}^{+}+$ $\mathrm{Al}+++$ do solo do local do experimento, calculou-se a quantidade de corretivo necessária para elevar o $\mathrm{pH}$ a 6,50 . Foi exigida a aplicação de $6.000 \mathrm{~kg} / \mathrm{ha}$. Os teores iniciais eram: $\mathrm{pH} 5,00$ e $\mathrm{H}++\mathrm{Al}+++$, 9,8 e.mg por $100 \mathrm{~g}$ de solo sêco.

O ensaio foi instalado em novembro de 1961 e concluído cm outubro de 1963. Imediatamente antes da aplicação do corretivo, procedeu-se à amostragem de cada canteiro.

Como a finalidade do ensaio era a de estudar o efeito do modo de aplicação de calcário, para aumento do valor de $\mathrm{pH}$, manteve-se o solo sem cultura, realizando-se, periòdicamente, roçamentos para eliminação da vegetação natural.

Durante os 22 meses de duração do ensaio, retiraram-se, mensalmente, amostras de solo de cada canteiro, para determinações potenciométricas dos teores de $\mathrm{pH}$. Cada amostra era composta de 10 subamostras retiradas com auxílio de trado, à profundidade de $0,15 \mathrm{~m}$. Cada amostra era analisada com três repetições.

\section{3 - RESUITADOS E DISCUSSÃO}

Os teores de $\mathrm{pH}$ observados durante o transcorrer do ensalio acham-se arrolados no quadro 1 e ilustrados na figura 1.

Verifica-se que o tratamento testemunha (sem calcário), apresentou valores de $\mathrm{pH}$ pouco variáveis ao redor do valor inicialmente determinado, que foi de 4.85. Obscrvou-se pequena elevação do $\mathrm{pH}$ entre os meses de março a junho de 1962. após o que os valores decresceram. pouco oscilando ao redor do inicial e encerrando-se o ensaio, após 22 meses, com o pH apresentando um teor igual a 4,80 .

Todos os outros tratamentos diferiram grandemente da testemunha nos valores de $\mathrm{pH}$, revelando alta eficiência, no combate à acidez do solo, de todos os métodos experimentados. 
Quadro 1. - Médias de valores de $\mathrm{pH}$ obtidas no ensaio de modo de aplicação de calcário, realizado na Estação Experimental do Departamento da Produção Animal, em Pindamonhangaba

\begin{tabular}{|c|c|c|c|c|c|c|}
\hline & $\begin{array}{l}\text { Meses após } \\
\text { aplicação do } \\
\text { corretivo }\end{array}$ & $\begin{array}{l}\text { Tratamen- } \\
\text { to } 1\end{array}$ & $\begin{array}{l}\text { Tratamen- } \\
\text { to } 2\end{array}$ & $\begin{array}{l}\text { Tratamen- } \\
\quad \text { to } 3\end{array}$ & $\begin{array}{l}\text { Tratamen- } \\
\quad \text { to } 4\end{array}$ & $\begin{array}{l}\text { Tratamen- } \\
\quad \text { to } 5\end{array}$ \\
\hline 0 & $\ldots \ldots \ldots$ & 4,85 & 4,75 & 4,80 & 4,90 & 5,10 \\
\hline 1 & $\ldots \ldots \ldots \ldots$ & 5,00 & 5,50 & 5,20 & 5,30 & 5,75 \\
\hline 2 & $\ldots \ldots \ldots \ldots \ldots$ & 4,85 & 5,75 & 5,50 & 5,20 & 6,00 \\
\hline 3 & $\ldots \ldots \ldots \ldots$ & 5,20 & 5,95 & 5,75 & 5,75 & 6,00 \\
\hline 4 & (*) $\ldots \ldots \ldots$ & $\cdots$ & $\cdots$ & $\cdots$ & -- & $\cdots$ \\
\hline$\tilde{j}$ & $\ldots \ldots \ldots \ldots \ldots$ & 5,10 & 6,15 & 5,80 & 5,75 & 6,20 \\
\hline 6 & $\ldots \ldots \ldots \ldots \ldots$ & 5,20 & 6,20 & 6,30 & 5,95 & 6,35 \\
\hline 7 & $\ldots \ldots \ldots \ldots$ & 5,00 & 6,50 & 6,15 & 6,45 & 6,50 \\
\hline 8 & $\ldots \ldots \ldots \ldots$ & 5,05 & 6,30 & 6,25 & 6,40 & 6,50 \\
\hline 9 & $\ldots \ldots \ldots \ldots$ & 5,00 & 6.45 & 6,40 & 6,50 & 6,65 \\
\hline 10 & $\ldots \ldots \ldots \ldots$ & 5,00 & 6,25 & 6,20 & 6,60 & 6,65 \\
\hline 11 & $\ldots \ldots \ldots \ldots$ & 4,90 & 6,15 & 6,40 & 6,10 & 6,30 \\
\hline 12 & $\ldots \ldots \ldots$ & 5,00 & 5,95 & 6,30 & 6,05 & 6,50 \\
\hline 13 & & 4,90 & 5,90 & 5,80 & 5,95 & 6,30 \\
\hline 14 & $\ldots \ldots \ldots$ & 4,80 & 6,00 & 5,95 & 6,25 & 6,30 \\
\hline 15 & $\ldots \ldots \ldots \ldots \ldots$ & 4,80 & 5,95 & 5,80 & 6,10 & 6,35 \\
\hline 16 & $\ldots \ldots$ & 4,75 & 6,15 & 6,05 & 6,00 & 6,10 \\
\hline 17 & $\ldots \ldots \ldots \ldots$ & 4,90 & 6,15 & 6,00 & 5,80 & 5,85 \\
\hline 18 & $\ldots \ldots \ldots \ldots$ & 4.85 & 5,85 & 5,65 & 5,60 & 5,70 \\
\hline 19 & $\ldots \ldots \ldots \ldots$ & 4,95 & 6,00 & 5,70 & 5,70 & 5,80 \\
\hline 20 & & 4,70 & 5,80 & 5,70 & 5,80 & 5,90 \\
\hline 21 & & 4,75 & 6,00 & 6,05 & 5,90 & 6,20 \\
\hline 22 & $\ldots \ldots \ldots \ldots \ldots$ & 4,80 & 6,15 & 6,35 & 6,10 & 6,40 \\
\hline
\end{tabular}

(*) As amostras correspondentes a ĉste mês foram acidentalmente perdidas.

Como pode ser fàcilmente observado no gráfico (figura 1), o tratamento 5 foi o que apresentou resultados mais rápidos, pois, um mês após a aplicação do corretivo, o $\mathrm{pH}$ atingiu $5,50 \mathrm{e}$, no segundo mês, 6,00 . Dessa data em diante, os valores de $\mathrm{pH}$ foram sempre crescentes até atingir o máximo nove meses após a instalação do ensaio.

O tratamento que, a seguir, apresentou mais rápida ação do calcário foi $\circ 2$, correspondente à aplicação do corretivo antes da aradura. No primeiro mês após a aplicação, o pH encontrado foi de 5,50, 


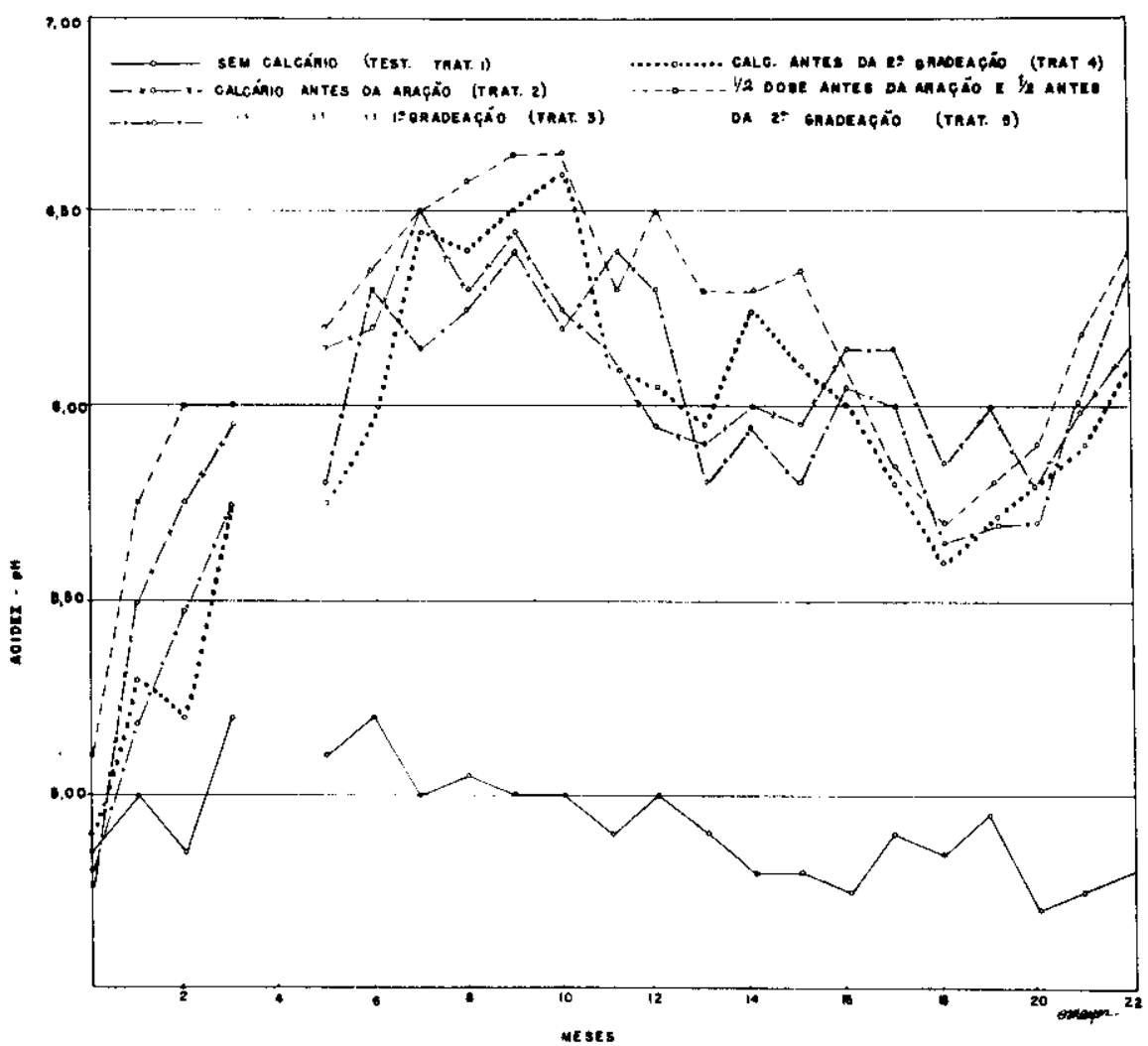

Ficura 1. - Curvas médias de pH obtidas no ensaio de modos de aplicaçăo de calcário, conduziło na Estação Experimental da Produção Animal, em Pindamonhangaba.

e no segundo, 5,75. No terceiro mês, o valor do $\mathrm{pH}$ se aproximou bastante do encontrado no tratamento 5 . Os valores determinados nos meses seguintes foram sempre crescentes, atingindo o máximo aos sete meses, com um pH igual a 6,50 .

A seguir colocou-se o tratamento 3 , em que o calcário foi aplicado após a aradura e antes das duas gradagens. A ação do corretivo se fêz sentir pela elevação do $\mathrm{pH}$, porém em espaço de tempo mais longo, pois sòmente no segundo mês após a aplicação é que se observou elevação sensivel no $\mathrm{pH}$, que atingiu 5,55. Nos meses subseqüentes as variações observadas foram pequenas ao redor dêsse valor, para finalmente, no sexto mês, atingir 6,15 , e sòmente no nono mês chegar ao valor mais alto, 6,45 . 
Finalmente, o tratamento cuja ação se mostrou mais lenta, foi o 4, em que o calcário foi aplicado antes da única gradagem. Efeito sensivel só foi observado a partir do terceiro mês, apresentando o valor de 5,60. No sétimo mês, porém, verificou-se que o valor atingiu 6,45 .

Os resultados obtidos confirmam a hipótese de que, quanto mais intimo o contato do corretivo com o solo, mais rápido se faz sentir seu efeito no aumento dos valores do pH, pois o tratamento que permitiu melhor mistura já apresentou efeitos pronunciados dois meses após a aplicação do calcário. É interessante observar, ainda, que, após nove meses da aplicação, todos os métodos utilizados apresentaram igualdade de respostas na elevação do $\mathrm{pH}$ do solo.

Os resultados obtidos mostram claramente que, dependendo da rapidez desejada no efeito do calcário, pode-se escolher qualquer dos métodos estudados. O fator importante a ser observado é a obtenção da perfeita união entre os materiais corretivos e as partículas de solo, quando se tem em vista a correção uniforme da acidez em tôda a área.

\section{$4-$ CONCLUSÕES}

Pelos resultados do ensaio aqui relatado, as seguintes conclusões podem ser tiradas:

1 - A aplicação do calcário promoveu grande redução da acidez dos solos, comprovada pelos valores de $\mathrm{pH}$ encontrados.

2 - O tratamento que mais rápido efeito apresentou na elevação do $\mathrm{pH}$ do solo foi aquêle em que a quantidade de corretivo foi dividida, aplicando-se metade antes da aradura e o restante antes da segunda gradagem. A seguir, em eficiência, colocou-se o tratamento em que o calcário foi aplicado antes da aradura.

3 - Entre o sétimo e o nono mês após a aplicação do calcário, todos os tratamentos apresentaram os valores de $\mathrm{pH}$ bastante próximos entre si, mostrando que, após êsse espaço de tempo, os quatro modos de aplicação estudados provocaram reduções idênticas na acidez do solo. 


\section{DIFFERENT MANNERS OF APPIICATION OF MATERIALS FOR CORRECTING SOII, ACIDI'TY}

\section{SUMMARY}

The experiment as reported in this paper had the purpose to stutly the effects of the manners in which to apply clay to the soil in order to correct its acidity.

During about two years this test has been continued in solls of the series Pinda, at the Experiment Station of the Departamento da Produção Animal, in the Pindamonhangaba county.

The clay was applied before plowing, before the first harrowing and before the second harrowing, or parcelled, that is, half before plowing and latf before the second harrowing.

\section{LITERATURA CITADA}

1. BUCKMAN, H. O. \& BRADY, N. C. I.ime and its soil plant relationship. Nature and Properties of Soils. New York, The MacMillan Co., 1961. p.386-408.

2. LENGENECKER, D. \& MERKLF, F. G. Influence of placement of lime compounds on root development and soil characteristics. Soil. Sci. 73: 71-74. 1952 .

3. MALAVolTA, E. Adubos cálcicos. Manual de Química Agrícola - Adubos e Adubação. São Paulo, Editora Agronômica «Ceres» Ltıla., 1959.

4. MIKKELSON, D. S., FREITAS, L. M. M. \& McCLUNG, A. C. Efeitos da calagem e adubação na produção de algodão, milho e soja em três solos de campo cerrado. São Paulo, Instituto de Pesquisas IRI, 1963. 48p. (Boletim No 29)

5. MII,I,AR, C. E. \& TURK, I. M. I,ime and its use. Fundamentais of Soil Science. New York, John Wiley \& Sons, Inc., 1951. p.134-165.

6. VERDADE, F. C., HUNGRIA, L. S., RUSSO, R. [e outros]. Solos da Bacia de Taubaté (Vale do Paraíba). Jevantamento de reconhecimento, séries monotípicas, suas propriedades genético-morfológicas, físicas e quimicas. Bragantia 20: 43-322, 1961.

7. WOR'THEN, E. J. \& ALDRICH, S. R. Liming to correct soil acidity. Farm Soils, Their Fertilization and Management. New York, John Wiley \& Sons, Inc. 1956. p.208-237. 